\title{
Analisis Video Likes To Image Likes Ratio Instagram Pada 10 Merk Kosmetik Lokal Terbaik
}

\author{
Luh Putu Rosita Yanti (19101002). \\ STMIK STIKOM Indonesia \\ puturosita2305@gmail.com
}

\begin{abstract}
ABSTRAK
Instagram, which is usually abbreviated as $\mathrm{IG}$, is a photo and video sharing application that allows users to take photos, take videos, apply digital filters, and share them on various social networking services, including Instagram's own. One unique feature on Instagram is cropping photos into square shapes, so they look like the results of Kodak Instamatic and Polaroid cameras. This is different from the 4:3 or 16:9 aspect ratio that is commonly used by cameras on mobile devices. Instagram can be used on any iPhone, iPad or iPod Touch version with the iOS 7.0 operating system or later, any Android mobile phone with the operating system version 2.2 (Froyo) and above, and Windows Phone 8. This application can be downloaded via the Apple App Store and Google Play. On April 9, 2012, it was announced that Facebook had agreed to take over Instagram for approximately $\$ 1$ billion. Instagram was first released on October 6, 2010, 11 years ago, the name Instagram Instagram comes from the understanding of the overall function of this application. The word "insta" comes from the word "instant", like the polaroid camera which at that time was better known as "instant photo". Instagram can also display photos instantly, like a polaroid in its display. As for the word "gram" comes from the word "telegram" which works to send information to others quickly. Similarly, Instagram can upload photos using the Internet, so the information you want to convey can be received quickly. That's why Instagram is an extension of the words instant and telegram. On April 9, 2012, it was announced that Instagram would be taken over by Facebook for nearly \$1 billion in cash and stock. On May 11, 2016, Instagram introduced a new look as well as a new icon and new app design. Inspired by previous app icons, the new icon is a simple camera and a vivid rainbow in the form of a gradient. There are 5 sandal vendors in Indonesia that use Instagram accounts as a marketing platform, namely: Dya_shoes, Dianable_, Yuma.co, Ilysproject, Bembiibloopshoes. The purpose of this study is to calculate the credibility of the Instagram account performance of the Top 5 Brand Sandals Vendors in Indonesia. The method used for this research is quantitative exploratory method. The results of this study indicate that the sandal vendor Dianable gets the first rank and has good account performance credibility.
\end{abstract}




\section{ABSTRAK}

Instagram yang biasanya disingkat IG adalah sebuah aplikasi berbagi foto dan video yang memungkinkan pengguna mengambil foto, mengambil video, menerapkan filter digital, dan membagikannya ke berbagai layanan jejaring sosial, termasuk milik Instagram sendiri. Satu fitur yang unik di Instagram adalah memotong foto menjadi bentuk persegi, sehingga terlihat seperti hasil kamera Kodak Instamatic dan polaroid. Hal ini berbeda dengan rasio aspek 4:3 atau 16:9 yang umum digunakan oleh kamera pada peranti bergerak. Instagram dapat digunakan di $\underline{\mathrm{iPhone}}, \underline{\mathrm{iPad}}$ atau $\underline{\mathrm{iPod} T o u c h}$ versi apapun

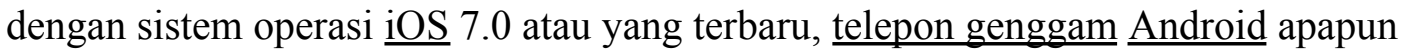
dengan sistem operasi versi 2.2 (royo) ke atas, dan Windows Phone 8. Aplikasi ini dapat diunduh melalui Apple App Store dan Google Play. Pada tanggal 9 April 2012, diumumkan bahwa Facebook setuju mengambil alih Instagram dengan nilai sekitar \$1 miliar. Instagram rilis perdana pada tanggal 6 Okntober 2010, 11 tahun yang lalu, Nama Instagram Instagram berasal dari pengertian dari keseluruhan fungsi aplikasi ini. Kata "insta" berasal dari kata "instan", seperti kamera polaroid yang pada masanya lebih dikenal dengan sebutan "foto instan". Instagram juga dapat menampilkan foto-foto secara instan, seperti polaroid di dalam tampilannya. Sedangkan untuk kata "gram" berasal dari kata "telegram" yang cara kerjanya untuk mengirimkan informasi kepada orang lain dengan cepat. Sama halnya dengan Instagram yang dapat mengunggah foto dengan menggunakan jaringan Internet, sehingga informasi yang ingin disampaikan dapat diterima dengan cepat. Oleh karena itulah Instagram merupakan lakuran dari kata instan dan telegram. Pada tanggal 9 April 2012, diumumkan bahwa Instagram akan diambil alih oleh Facebook senilai hampir \$1 miliar dalam bentuk tunai dan saham. Pada tanggal 11 Mei 2016, Instagram memperkenalkan tampilan baru sekaligus ikon baru dan desain aplikasi baru. Terinspirasi oleh ikon aplikasi sebelumnya, ikon baru merupakan kamera sederhana dan pelangi hidup dalam bentuk gradien. Adapun 10 Merk Kosmetik Lokal di Indonesia yang memanfaatkan akun Instagram sebagai platform marketing, yaitu : eminacosmetics, wardahbeauty, makeoverid, mokomoko_id, rollover.reaction, purbasarimakeupid, blpbeauty, mustikaratuind, gobancosmetics, esqacosmetics, Tujuan dari penelitian ini yaitu untuk menghitung kredibilitas dari performa akun Instagram Top 10 Merk Kosmetik Lokal Terbaik. Metode yang digunakan untuk penelitian ini yaitu metode eksploratif kuantitatif. Hasil dari penelitian ini menunjukan bahwa vendor kosmetik lokal terbaik Mustika ratu mendapatkan peringkat pertama dan memiliki kredibilitas performa akun yang baik.

Keyword : Instagram Account Credibility, Social media marketing, Instagram Social Media, Video Likes to Image Likes Rate, Cosmetics Local Vendor in Indonesia 


\section{PENDAHULUAN}

Teknologi Informasi yang biasanya di sebut dengan (TI) dalah istilah umum untuk teknologi apa pun yang membantu manusia dalam membuat, mengubah, menyimpan, mengomunikasikan dan atau menyebarkan informasi. TI menyatukan komputasi dan komunikasi berkecepatan tinggi untuk data, suara, dan video. Contoh dari Teknologi Informasi bukan hanya berupa komputer pribadi, tetapi juga telepon, TV, peralatan rumah tangga elektronik, dan peranti genggam modern (misalnya ponsel). Pengolahan, penyimpanan dan penyebaran vokal, informasi bergambar, teks dan numerik oleh

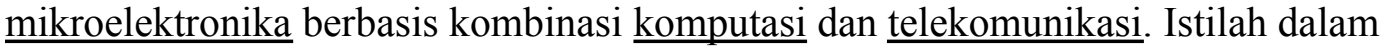
pengertian modern pertama kali muncul dalam sebuah artikel 1958 yang diterbitkan dalam Harvard Business Review, di mana penulis Leavitt dan Whisler berkomentar bahwa "teknologi baru belum memiliki nama tunggal yang didirikan. Kita akan menyebutnya teknologi informasi (TI). Beberapa bidang modern yang muncul dari teknologi informasi adalah generasi berikutnya teknologi web, bioinformatika, "Cloud Computing", sistem informasi global, Skala besar basis pengetahuan dan lain-lain.

Maka dengan pesatnya perkembangan teknologi media sosial, telah memberikan dampak terhadap situs-situs komunikasi, dari yang awalnya hanya sekedar email dan chatting, saat ini sudah banyak jejaring media sosial yang bisa digunakan sebagai alat komunikasi. Contoh aplikasi sosial media yang memiliki banyak pengguna saat ini yaitu Instagram. Instagram merupakan aplikasi yang diluncurkan oleh perusahaan asal perusahaan Burbn, Inc. Instagram memungkinkan penggunanya membuat video berdurasi 15 detik yang disertai dengan musik, filter, dan beberapa fitur kreatif lainnya. Dengan kehadiran media sosial Instagram dapat membangun sebuah brand, Instagram juga dapat membangun personal branding pemiliknya (Kevin Systrom dan Mike Krieger 2010). Di Indonesia, terdapat 91,77 juta pengguna Instagram yang aktif sehingga menjadikan Indonesia sebagai negara dengan pengguna Instagram terbesar di dunia. Maraknya jumlah pengguna Instagram aktif di Indonesia tentu dapat memberikan peluang bagi brand untuk menjadikan platform ini sebagai platform social media marketing. Cukup banyak akun perushaan-perusahaan terkenal yang ada pada instagram, contohnya seperti vendor kosmetik lokal di Indonesia. Adapun 10 Merk Kosmetik Lokal terbaik, diantaranya yaitu : eminacosmetics, wardahbeauty, makeoverid, mokomoko_id, rollover.reaction, purbasarimakeupid, blpbeauty, mustikaratuind, gobancosmetics, esqacosmetics

Penelitian ini menggunakan metode eksploratif kuantitatif, dan akan menghitung menggunakan rasio-rasio yang ada pada Instagram. Pada menjelaskan bahwa terdapat 12 
rasio yang ada pada sosial media Instagram dan relevan digunakan sebagai media ukur kredibilitas akun yang ada. Penelitian ini hanya berfokus untuk menghitung kredibilitas Video Likes to Image Likes Ratio pada 10 Merk Kosmetik Lokal terbaik . Adapun 10 Merk Kosmetik Lokal terbaik , diantaranya yaitu : eminacosmetics, wardahbeauty, makeoverid, mokomoko_id, rollover.reaction, purbasarimakeupid, blpbeauty, mustikaratuind, gobancosmetics, esqacosmetics . Tujuan dari penelitian ini adalah mengetahui kredibilitas performa dari akun Instagram Top 10 Merk Kosmetik Lokal terbaik menggunakan Video Likes to Image Likes Ratio.

Berikut berita linknya (Tokopedia, 2020)

Tokopedia. (2020). 10 Merk Kosmetik Lokal Terbaik. Https:/Www.Tokopedia.Com/. https://www.tokopedia.com/blog/top-brand-kosmetik-lokal-terbaik/

Penelitian ini berpacu pada hasil rasio yang ditemukan pada penelitian yang telah terjadi, berikut merupakan link penelitian untuk sitasi rasio yang didapatkan.

Rasio Instagram : https://www.infoteks.org/journals/index.php/jsikti/article/view/109

\section{TINJAUAN PUSTAKA}

Perkembangan dalam bidang teknologi saat ini terjadi sangat pesat, perkembangan teknologi saat ini menimbulkan banyak aplikasi serta platform media sosial yang bermunculan. Aplikasi yang sangat diminati oleh masyarakat saat ini diantaranya

adalah TikTok, Instagram, Twitter, WhatsApp, Facebook dan yang lain sebagainya. Seiring berjalannya waktu, aplikasi sosial media tersebut dapat menjadi candu bagi kalangan masyarakat. Tidak hanya kalangan anak remaja yang menggunakan aplikasi sosial media, hingga orang tua bahkan anak-anak juga aktif menggunakan aplikasi sosial media tersebut.

Instagram merupakan jejaring sosial media dalam bentuk video yang umumnya berdurasi 15 detik. Pada aplikasi Instagram pengguna dapat membuat video dengan filter-filter yang sudah tesedia pada akun isntagram tersebut serta menggunakan lagu yang sedang trending. Selain itu, pengguna dapat membagikan video yang dibuat ke aplikasi lain seperti Tiktok. Salah satu ciri khas sosial media Instagram adalah halaman utamanya yang Bernama For Your Page atau FYP. Pengguna yang cukup sering ditayangkan dalam FYP dapat menjadi populer dan memiliki banyak pengikut, yang biasa disebut sebagai seleb Instagram.

Di Indonesia, para anak muda maupun orang tua dalam menggunakan Instagram menunjukan antusiasme yang sangat massif. Meraka berlomba membangun identitas demi mendapatkan citra yang diinginkan, seperti dipuji dan dikenal oleh banyak orang.

Aplikasi Instagram semakin populer sejak diluncurkan tahun 2010. Aplikasi Instagram tidak hanya digunakan untuk membuat konten video dengan tujuan 
menghibur pengguna lainnya. Aplikasi Instagram juga dapat dijadikan peluang bagi brand atau perusahaan sebagai platform sosial media marketing.

Akun Instagram berpengaruh positif dan signifikan terhadap minat beli atau berbelanja secara online. Sehingga dengan ini, Instagram mampu memberikan peluang yang sangat tinggi bagi perusahaan-perusahaan dalam melakukan digital marketing. Instagram dirasakan memiliki kekuatan ataupun pengaruh dalam industri, sehingga menimbulkan kualitas akun yang menentukan strata maupun kredibilitas pemilik akun. Kredibilitas akun Instagram merupakan suatu hal yang cukup penting untuk berbagai kepentingan. Kredibilitas sebuah akun Instagram dapat diukur dari tingkat performa yang dihasilkan secara matematis. Dalam mengukur performa diperlukan skala pengukuran yang tertuang ke dalam rasio.

\section{METODE PENELITIAN}

Penelitian ini menggunakan metode eksploratif kuantitatif untuk mengetahui kredibilitas dari performa akun Instagram 10 Merk Kosmetik Lokal terbaik 2021. Metode eksploratif merupakan penelitian yang memiliki tujuan untuk melakukan eksplorasi atau memperdalam pengetahuan ataupun ide-ide baru mengenai suatu hal yang baru, guna merumuskan permasalahan secara terperinci. Tujuan dari penelitian ini yaitu mengetahui nilai kredibillitas dari performa akun Instagram 10 Merk Kosmetik Lokal Terbaik 2021. Ada beberapa langkah yang harus dilakukan dalam penelitian ini, sehingga mampu menemukan peringkat pertama akun Instagram Merk Kosmetik lokal tebaik yang memiliki performa terbaik. Langkah-langkah yang dilakukan pada penelitian ini, diantaranya yaitu :

\section{Melakukan Eksplorasi Pada Website Untuk Menentukan Objek yang Akan}

\section{Dianalisa.}

Eksplorasi ini dilakukan pada beberapa halaman website yang menyediakan informasi mengenai objek yang akan di teliti. Setelah eksplorasi selesai dilakukan, sehingga ditemukan nama-nama merk kosmetik local terbaik yang akan dijadikan objek analisa. Setelah melakukan eksplorasi pada halaman website, maka langkah selanjutnya yaitu mencari nama akun Instagram dari masing-masing vendor kosmetik lokal. Pastikan semua vendor memiliki akun pada aplikasi sosial media Instagram.

\section{Menghitung Nilai Rata-Rata Variable Dari 10 Merk Kosmetik Lokal Terbaik.}

Pada langkah ini, peneliti menghitung nilai variable video lokes dan variable image likes. Variabel merupakan sesuatu yang memiliki nilai bervariasi dimana nilai tersebut 
dapat dijadikan sebagai dasar untuk empat data yang berbeda seperti rasio, skala, ordinal, nominal dan internal. Untuk menghitung nilai rata-rata dari variabel video likes dan variabel images likes yaitu dengan cara mengambil minimal 10 postingan kemudian di hitung sehingga menemukan nilai rata-rata dari masing-masing variabel.

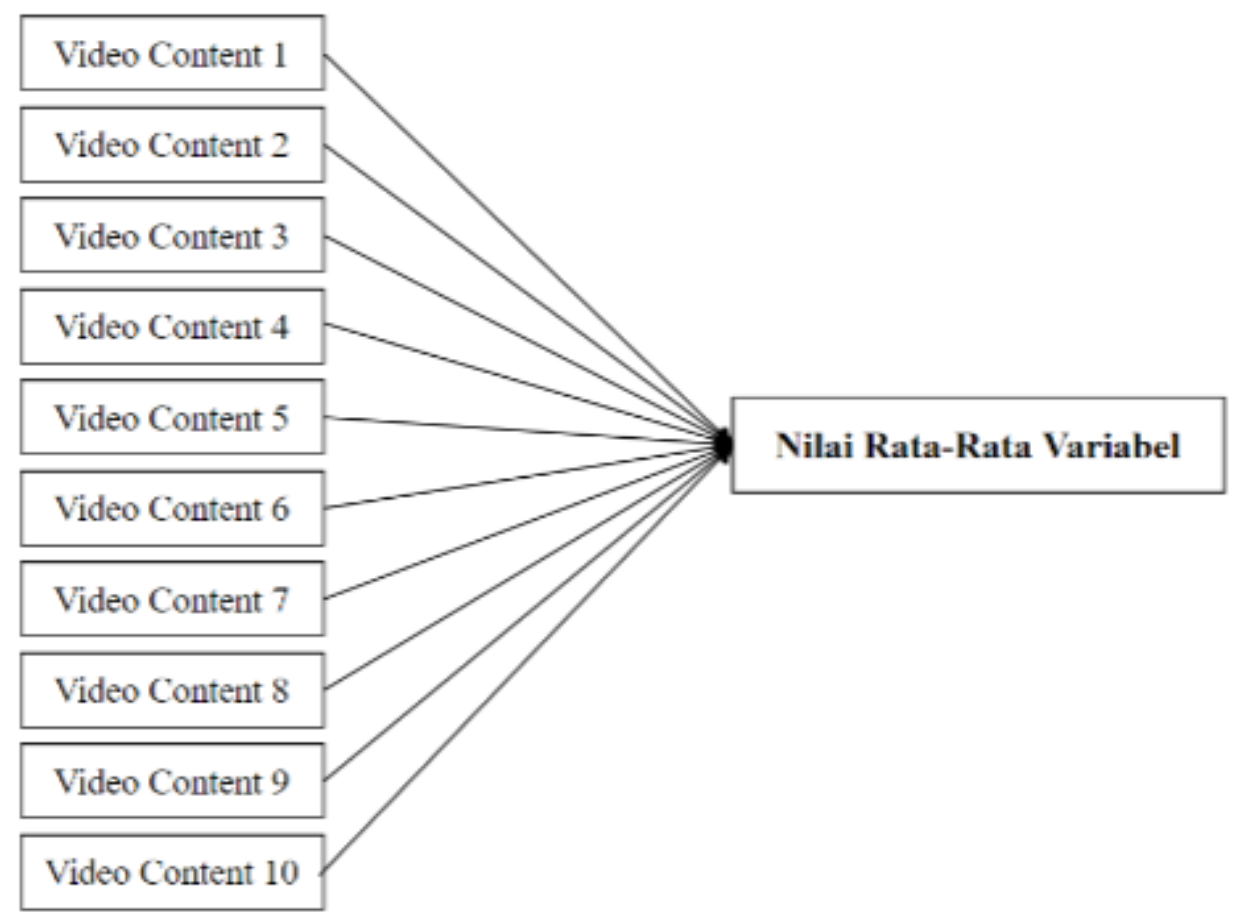

Gambar 1. Analisa Nilai Rata-Rata Variabel.

\section{Menghitung Nilai Kredibilitas Rasio}

Untuk menghitung nilai kredibilitas dari video likes to images likes ratio, peneliti menggunakan cara membagi nilai variabel pertama dengan nilai variabel kedua. Jika video comments memiliki nilai 100 dan video likes memiliki nilai 300, maka 
cara menghitungnya yaitu $100: 300=0,3$. Dengan begitu nilai dari video likes to image likes ratio adalah 0,3 .

\section{Menentukan Peringkat Pada Akun Instagram}

Pada langkah terakhir yang dilakukan pada penelitian ini yaitu menentukan peringkat pada masing-masing rasio yang ada. Pada penentuan peringkat perlu melihat karakteristik dari rasio yang di teliti. Jika karakteristik rasio merupakan rendah, maka objek yang memiliki nilai terendah akan mendapatkan angka 10 dan objek yang memiliki nilai tertinggi akan mendapatkan angka 1. Namun jika rasio memiliki karakteritik tinggi maka objek yang mendapatkan nilai tinggi akan mendapatkan angka 10 dan objek yang mendapatkan nilai terendah akan mendapatkan angka 1. Setelah mendapatkan hasil kredibilitas ratio maka dapat disimpulkan objek yang mana mendapatkan peringkat 1 sampai dengan peringkat 10

\section{HASIL DAN PEMBAHASAN}

Akun Instagram dari 10 Merk Kosmetik Lokal Terbaik diantaranya :

\section{Eminacosmetics}

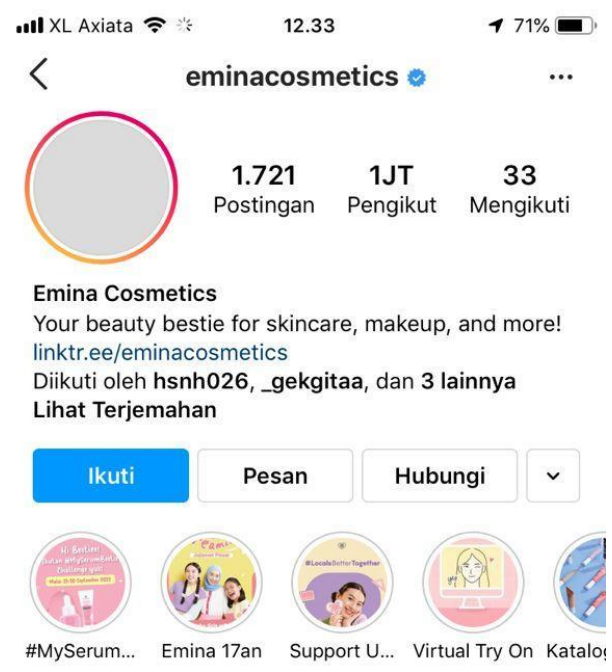

Sumber : https://instagram.com/eminacosmetics?utm_medium=copy link (akses pada 20-10-2021)

2. wardahbeauty 


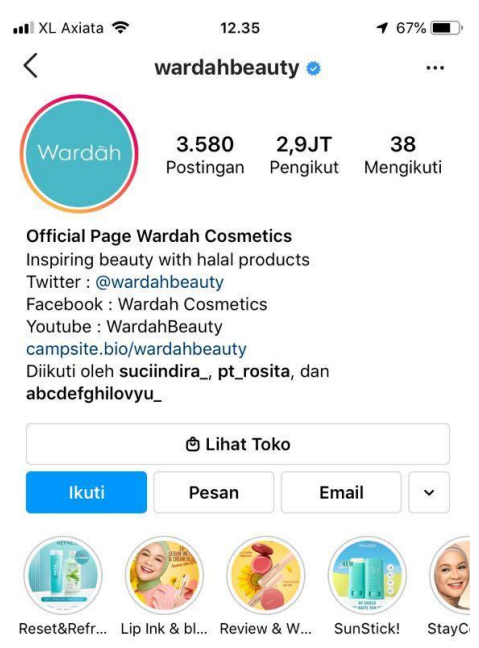

Sumber : https://instagram.com/wardahbeauty?utm_medium=copy link (akses pada 20-10-2021)

\section{3. makeoverid}

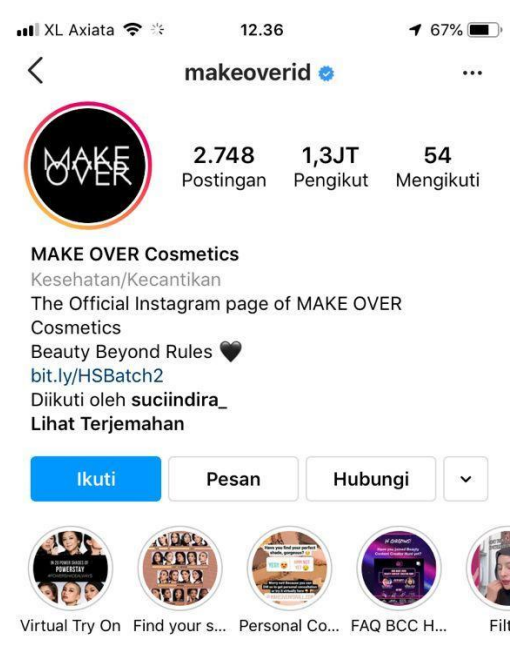

Sumber : https://instagram.com/makeoverid?utm_medium=copy_link (akses pada 20-10-2021)

4. mokomoko_id 


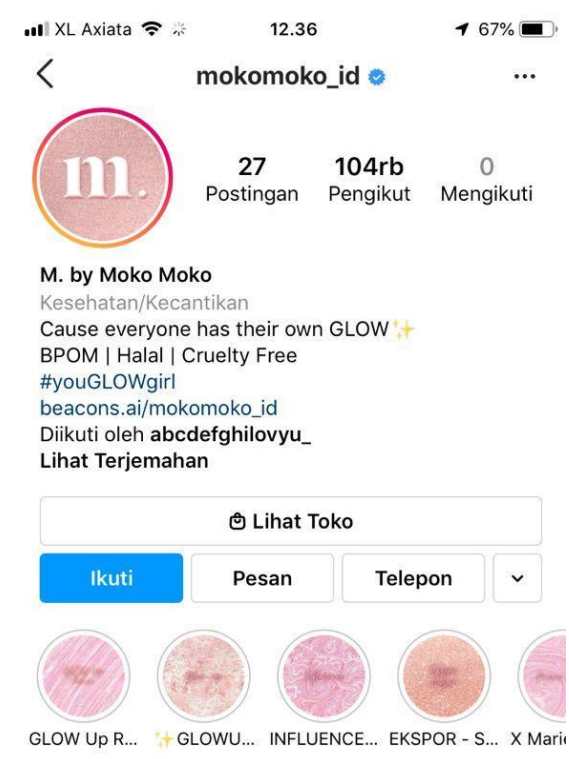

Sumber : https://instagram.com/mokomoko id?utm medium=copy link (akses pada 20-10-2021)

5. rollover.reaction

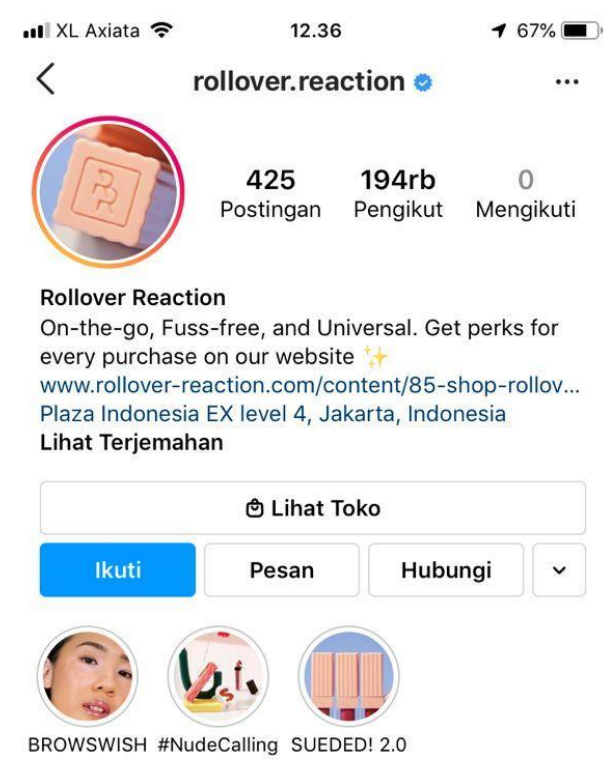

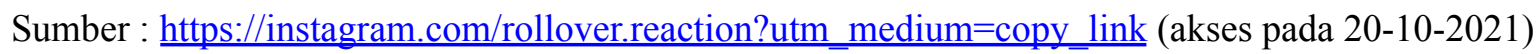


6. purbasarimakeupid

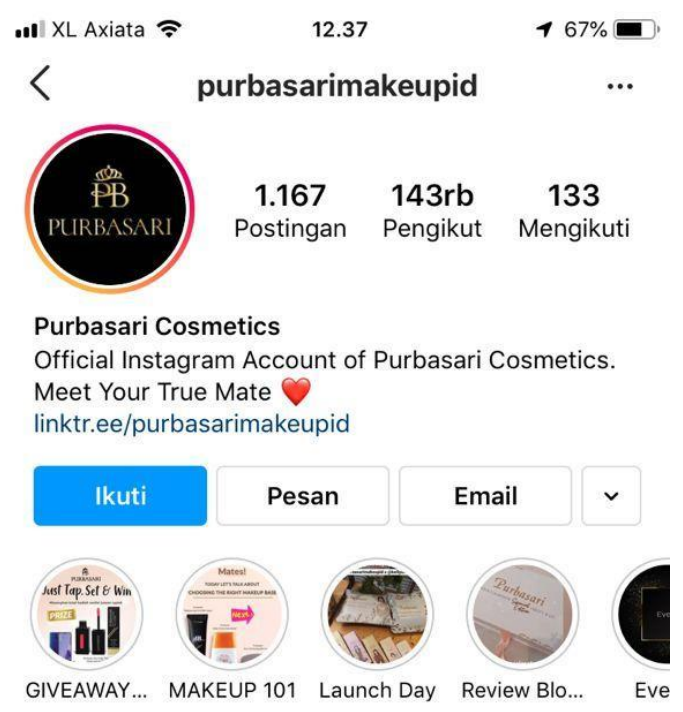

Sumber : https://instagram.com/purbasarimakeupid?utm medium=copy link (akses pada 20-10-2021)

7. blpbeauty 


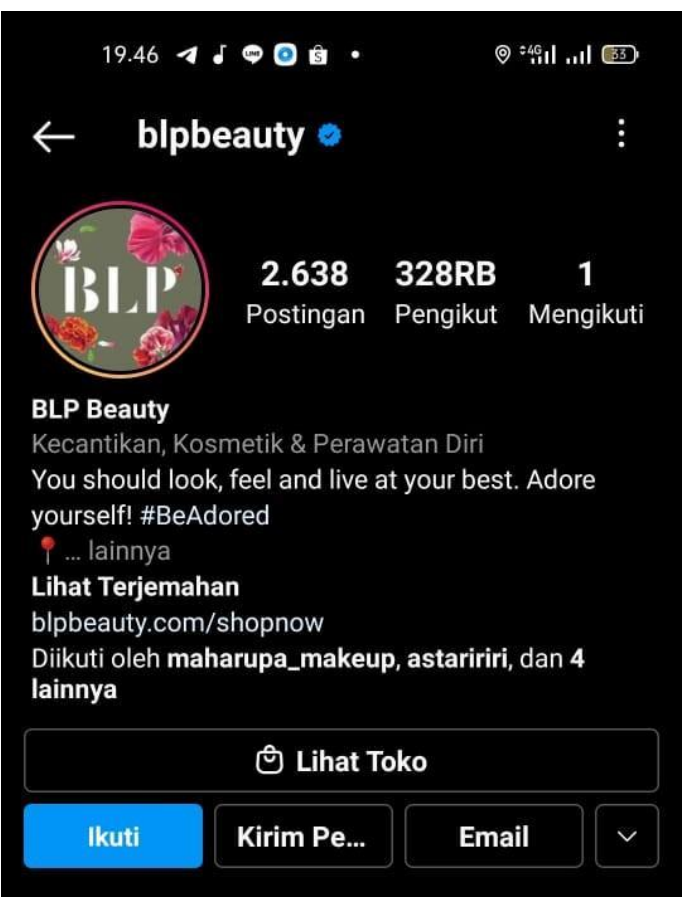

Sumber : https://instagram.com/blpbeauty?utm medium=copy link (akses pada 20-10-2021)

8. mustikaratuind

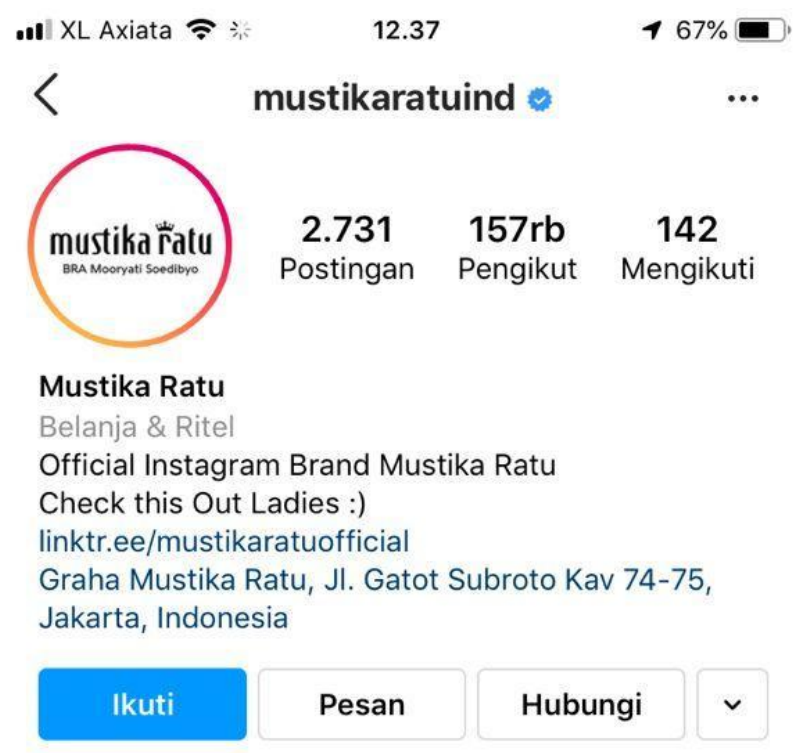

Sumber : https://instagram.com/mustikaratuind?utm_medium=copy link (akses pada 20-10-2021) 


\section{9. gobancosmetics}

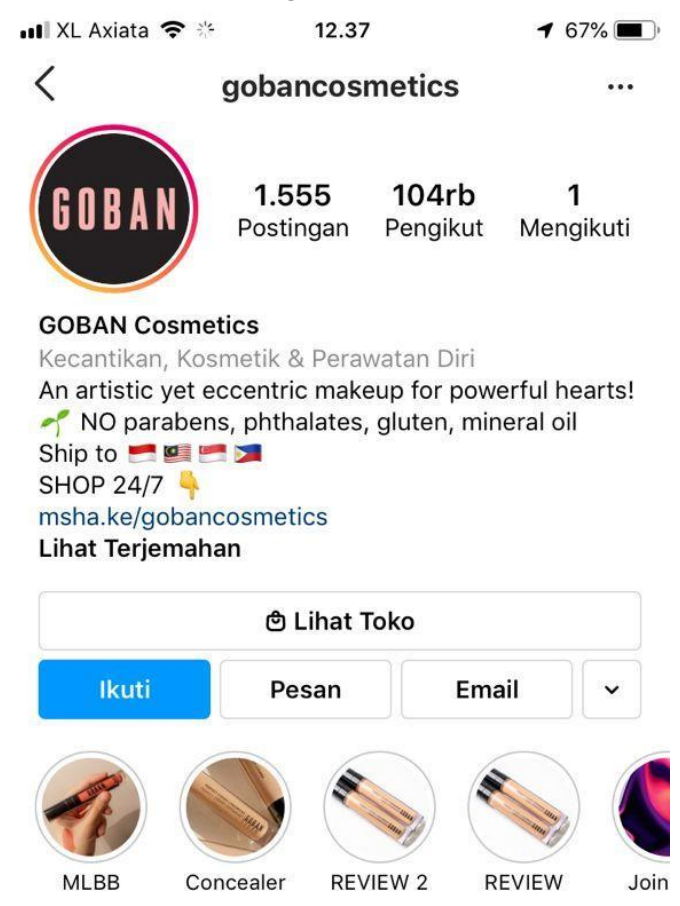

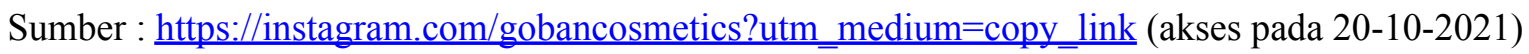

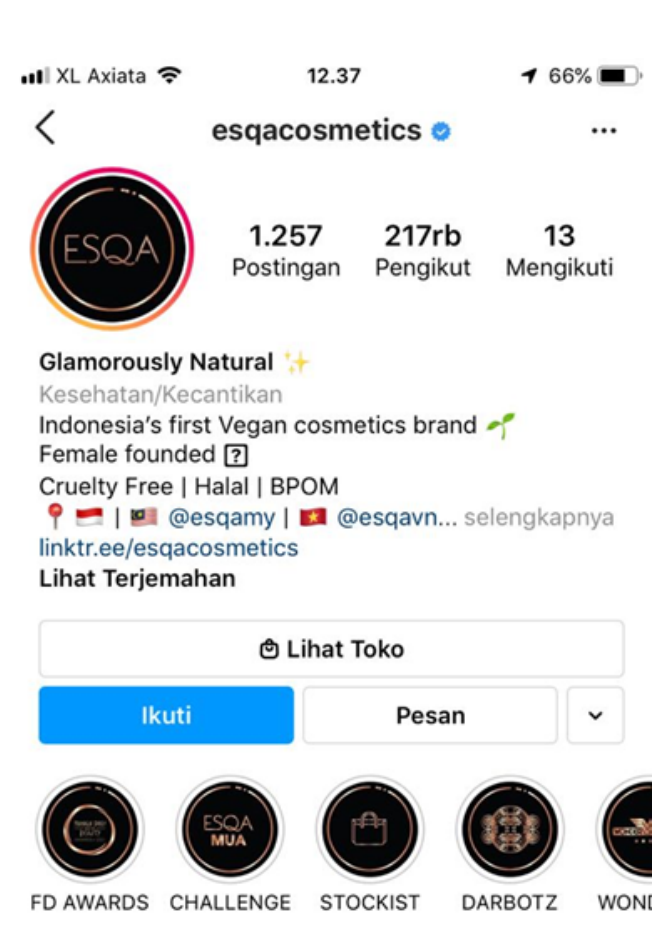

10. esqacosmetics 
Sumber : https://instagram.com/esqacosmetics?utm medium=copy link (akses pada 20-10-2021)

Dari variabel tersebut peneliti hanya fokus untuk menemukan hasil dari 2 variabel,

yaitu :

1. Video like

2. Image like

3. Followers

Dari variabel tersebut kemudian dianalisa sehingga menemukan nilai rata-rata dari Video to Likes to Images Likes to Follower ratio yaitu dengan cara mengambil minimal 10 produk kemudian di hitung sehingga menemukan nilai rata-rata dari masing-masing variabel. Berikut merupakan tabel nilai rata-rata dari masing-masing Brand :

EMINA

\begin{tabular}{|c|c|c|c|}
\hline NO & Video Likes & Images Likes & Followers Ratio \\
\hline 1 & 1163 & 850 & 1000000 \\
\hline 2 & 1207 & 8290 & 1000000 \\
\hline 3 & 1284 & 3585 & 1000000 \\
\hline 4 & 1195 & 9821 & 1000000 \\
\hline 5 & 1358 & 2369 & 1000000 \\
\hline 6 & 2337 & 2867 & 1000000 \\
\hline 7 & 1314 & 1544 & 1000000 \\
\hline 8 & 2302 & 7070 & 1000000 \\
\hline 9 & 1110 & 4301 & 1000000 \\
\hline 10 & 3204 & 7676 & 1000000 \\
\hline Total & 1647.4 & 4837.3 & 1000000 \\
\hline
\end{tabular}




\section{MAKEOVER}

\begin{tabular}{|c|c|c|c|}
\hline NO & Video Likes & Images Likes & Followers Ratio \\
\hline 1 & 876 & 1094 & 3000000 \\
\hline 2 & 1021 & 2059 & 3000000 \\
\hline 3 & 1421 & 1552 & 3000000 \\
\hline 4 & 1362 & 2224 & 3000000 \\
\hline 5 & 1688 & 1675 & 3000000 \\
\hline 6 & 876 & 2386 & 3000000 \\
\hline 7 & 1422 & 4894 & 3000000 \\
\hline 8 & 2974 & 2786 & 3000000 \\
\hline 9 & 2263 & 5917 & 3000000 \\
\hline 10 & 2389 & 1954 & 3000000 \\
\hline Total & 1544.777778 & 2654.1 & 3000000 \\
\hline
\end{tabular}

МОКО-МОКО

\begin{tabular}{|c|c|c|c|}
\hline No & Video Likes & Images Likes & Followers Ratio \\
\hline 1 & 173 & 419 & 1300000 \\
\hline 2 & 400 & 414 & 1300000 \\
\hline 3 & 990 & 586 & 1300000 \\
\hline 4 & 1119 & 2621 & 1300000 \\
\hline 5 & 2075 & 3546 & 1300000 \\
\hline 6 & 753 & 1407 & 1300000 \\
\hline 7 & 500 & 1811 & 1300000 \\
\hline 8 & 847 & 470 & 1300000 \\
\hline 9 & 5546 & 1112 & 1300000 \\
\hline 10 & 2128 & 1058 & 1300000 \\
\hline Total & 1453.1 & 1344.4 & 1300000 \\
\hline
\end{tabular}




\section{GOBAN}

\begin{tabular}{|c|c|c|c|}
\hline No & Video Likes & Images Likes & Followers Ratio \\
\hline 1 & 225 & 31 & 104000 \\
\hline 2 & 74 & 67 & 104000 \\
\hline 3 & 289 & 62 & 104000 \\
\hline 4 & 160 & 57 & 104000 \\
\hline 5 & 188 & 64 & 104000 \\
\hline 6 & 13 & 86 & 104000 \\
\hline 7 & 40 & 107 & 104000 \\
\hline 8 & 137 & 67 & 104000 \\
\hline 9 & 375 & 185 & 104000 \\
\hline 10 & 295 & 60 & 104000 \\
\hline Total & 179.6 & 78.6 & 104000 \\
\hline
\end{tabular}

\section{ESQA}

\begin{tabular}{|c|c|c|c|}
\hline No & Video Likes & Images Likes & Followers Ratio \\
\hline 1 & 1410 & 52 & 193000 \\
\hline 2 & 172 & 252 & 193000 \\
\hline 3 & 100 & 175 & 193000 \\
\hline 4 & 118 & 121 & 193000 \\
\hline 5 & 138 & 655 & 193000 \\
\hline 6 & 128 & 1008 & 193000 \\
\hline 7 & 261 & 144 & 193000 \\
\hline 8 & 268 & 251 & 193000 \\
\hline 9 & 1590 & 548 & 193000 \\
\hline 10 & 340 & 90 & 193000 \\
\hline
\end{tabular}




\section{WARDAH}

\begin{tabular}{|c|c|c|c|}
\hline No & Video Likes & Images Likes & Followers Ratio \\
\hline 1 & 1856 & 93 & 143000 \\
\hline 2 & 229 & 162 & 143000 \\
\hline 3 & 869 & 495 & 143000 \\
\hline 4 & 157 & 1016 & 143000 \\
\hline 5 & 987 & 365 & 143000 \\
\hline 6 & 306 & 289 & 143000 \\
\hline 7 & 345 & 359 & 143000 \\
\hline 8 & 342 & 433 & 143000 \\
\hline 9 & 394 & 474 & 143000 \\
\hline 10 & 459 & 2035 & 143000 \\
\hline Total & 594.4 & 572.1 & 143000 \\
\hline
\end{tabular}

ROLLOVER

\begin{tabular}{|c|c|c|c|}
\hline No & Video Likes & Images Likes & Followers Ratio \\
\hline 1 & 40 & 333 & 328000 \\
\hline 2 & 104 & 1888 & 328000 \\
\hline 3 & 56 & 6152 & 328000 \\
\hline 4 & 656 & 340 & 328000 \\
\hline 5 & 646 & 282 & 328000 \\
\hline 6 & 370 & 376 & 328000 \\
\hline 7 & 268 & 257 & 328000 \\
\hline 8 & 323 & 402 & 328000 \\
\hline 9 & 206 & 15236 & 328000 \\
\hline
\end{tabular}




\begin{tabular}{|c|c|c|c|}
\hline 10 & 848 & 835 & 328000 \\
\hline Total & 351.7 & 2610.1 & 328000 \\
\hline
\end{tabular}

PURBASARI

\begin{tabular}{|c|c|c|c|}
\hline No & Video Likes & Images Likes & Followers Ratio \\
\hline 1 & 1856 & 93 & 143000 \\
\hline 2 & 229 & 162 & 143000 \\
\hline 3 & 869 & 495 & 143000 \\
\hline 4 & 157 & 1016 & 143000 \\
\hline 5 & 987 & 365 & 143000 \\
\hline 6 & 306 & 289 & 143000 \\
\hline 7 & 345 & 359 & 143000 \\
\hline 8 & 342 & 433 & 143000 \\
\hline 9 & 394 & 474 & 143000 \\
\hline 10 & 459 & 2035 & 143000 \\
\hline Total & 594.4 & 572.1 & 143000 \\
\hline
\end{tabular}

\section{BLP}

\begin{tabular}{|c|c|c|c|}
\hline No & Video Likes & Images Likes & Followers Ratio \\
\hline 1 & 40 & 333 & 328000 \\
\hline 2 & 104 & 1888 & 328000 \\
\hline 3 & 56 & 6152 & 328000 \\
\hline 4 & 656 & 340 & 328000 \\
\hline 5 & 646 & 282 & 328000 \\
\hline 6 & 370 & 376 & 328000 \\
\hline 7 & 268 & 257 & 328000 \\
\hline 8 & 323 & 402 & 328000 \\
\hline
\end{tabular}




\begin{tabular}{|c|c|c|c|}
\hline 9 & 206 & 15236 & 328000 \\
\hline 10 & 848 & 835 & 328000 \\
\hline Total & 351.7 & 2610.1 & 328000 \\
\hline
\end{tabular}

MUSTIKA

\begin{tabular}{|c|c|c|c|}
\hline No & Video Likes & Images Likes & Followers Ratio \\
\hline 1 & 320 & 90 & 157000 \\
\hline 2 & 118 & 387 & 157000 \\
\hline 3 & 744 & 164 & 157000 \\
\hline 4 & 175 & 193 & 157000 \\
\hline 5 & 584 & 302 & 157000 \\
\hline 6 & 600 & 239 & 157000 \\
\hline 7 & 241 & 278 & 157000 \\
\hline 8 & 214 & 207 & 157000 \\
\hline 9 & 236 & 237 & 157000 \\
\hline 10 & 162 & 312 & 157000 \\
\hline Total & 339.4 & 240.9 & 157000 \\
\hline
\end{tabular}

KALKULASI SETIAP VARIABEL

\begin{tabular}{|c|c|c|c|}
\hline No & $\begin{array}{c}\text { Video } \\
\text { Likes }\end{array}$ & $\begin{array}{c}\text { Images } \\
\text { Likes }\end{array}$ & $\begin{array}{c}\text { Followers } \\
\text { Ratio }\end{array}$ \\
\hline 1 & 320 & 90 & 157000 \\
\hline 2 & 118 & 387 & 157000 \\
\hline 3 & 744 & 164 & 157000 \\
\hline 4 & 175 & 193 & 157000 \\
\hline 5 & 584 & 302 & 157000 \\
\hline 6 & 600 & 239 & 157000 \\
\hline
\end{tabular}




\begin{tabular}{|c|c|c|c|}
\hline 7 & 241 & 278 & 157000 \\
\hline 8 & 214 & 207 & 157000 \\
\hline 9 & 236 & 237 & 157000 \\
\hline 10 & 162 & 312 & 157000 \\
\hline $\begin{array}{c}\text { Tota } \\
1\end{array}$ & 339.4 & 240.9 & 157000 \\
\hline
\end{tabular}

\begin{tabular}{|c|c|c|c|}
\hline No & $\begin{array}{c}\text { Video } \\
\text { Likes }\end{array}$ & $\begin{array}{c}\text { Images } \\
\text { Likes }\end{array}$ & $\begin{array}{c}\text { Followera } \\
\text { Ratio }\end{array}$ \\
\hline 1 & 111 & 30 & 104000 \\
\hline 2 & 55 & 38 & 104000 \\
\hline 3 & 148 & 78 & 104000 \\
\hline 4 & 136 & 56 & 104000 \\
\hline 5 & 28 & 72 & 104000 \\
\hline 6 & 65 & 58 & 104000 \\
\hline 7 & 44 & 39 & 104000 \\
\hline 8 & 406 & 118 & 104000 \\
\hline 9 & 55 & 107 & 104000 \\
\hline 10 & 78 & 123 & 104000 \\
\hline $\begin{array}{c}\text { Tota } \\
\text { I }\end{array}$ & 112.6 & 71.9 & 1040000 \\
\hline
\end{tabular}

\begin{tabular}{|c|c|c|c|}
\hline No & Video Likes & Images Likes & Followers Ratio \\
\hline 1 & 640 & 1919 & 216000 \\
\hline 2 & 132 & 507 & 216000 \\
\hline 3 & 220 & 509 & 216000 \\
\hline 4 & 3467 & 541 & 216000 \\
\hline 5 & 608 & 696 & 216000 \\
\hline
\end{tabular}




\begin{tabular}{|c|c|c|c|}
\hline 6 & 603 & 499 & 216000 \\
\hline 7 & 1121 & 420 & 216000 \\
\hline 8 & 2156 & 1081 & 216000 \\
\hline 9 & 2235 & 1399 & 216000 \\
\hline 10 & 1669 & 759 & 216000 \\
\hline Total & 1285.1 & 833 & 216000 \\
\hline
\end{tabular}

Dari sini dimulailah pencarian rata rata dan rasio setiap data

Berikut merupakan tabel urutan nilai yang dihasilkan oleh masing-masing brand

\begin{tabular}{|c|c|c|c|c|c|c|c|c|c|c|}
\hline $\begin{array}{l}\mathrm{V} \\
\mathrm{a} \\
\mathrm{r} \\
\mathrm{i} \\
\mathrm{a} \\
\mathrm{b} \\
\mathrm{e} \\
1\end{array}$ & $\begin{array}{l}\text { Em } \\
\text { ina } \\
\text { Co } \\
\text { sm } \\
\text { eti } \\
\text { cs }\end{array}$ & $\begin{array}{l}\text { Warda } \\
\mathrm{h} \\
\text { beauty }\end{array}$ & $\begin{array}{c}\text { Make } \\
\text { over } \\
\text { id }\end{array}$ & $\begin{array}{c}\text { Mok } \\
\text { o } \\
\text { mok } \\
\text { o id }\end{array}$ & $\begin{array}{c}\text { Rollo } \\
\text { ver } \\
\text { React } \\
\text { ion }\end{array}$ & $\begin{array}{c}\text { Purbas } \\
\text { ari }\end{array}$ & $\begin{array}{c}\text { By } \\
\text { Lizzi } \\
\text { e } \\
\text { Parr } \\
\text { a } \\
\text { (BL } \\
\text { P) }\end{array}$ & $\begin{array}{c}\text { Mustika } \\
\text { Ratu }\end{array}$ & $\begin{array}{c}\text { Goba } \\
\text { n } \\
\text { Cos } \\
\text { meti } \\
\text { cs }\end{array}$ & $\begin{array}{l}\text { Esqa } \\
\text { Cosme } \\
\text { tics }\end{array}$ \\
\hline $\begin{array}{l}\mathrm{V} \\
\mathrm{i} \\
\mathrm{d} \\
\mathrm{e} \\
\mathrm{o} \\
\mathrm{L} \\
\mathrm{i} \\
\mathrm{k} \\
\mathrm{e} \\
\mathrm{s}\end{array}$ & $\begin{array}{c}16 \\
47 . \\
4\end{array}$ & $\begin{array}{l}1544.7 \\
77778 \\
\end{array}$ & $\begin{array}{c}1453 . \\
1 \\
\end{array}$ & $\begin{array}{c}179 . \\
6 \\
\end{array}$ & 452.5 & 594.4 & $\begin{array}{c}351 . \\
7 \\
\end{array}$ & 339.4 & $\begin{array}{c}112 . \\
6 \\
\end{array}$ & 1285.1 \\
\hline $\begin{array}{l}\mathrm{I} \\
\mathrm{m} \\
\mathrm{a} \\
\mathrm{g} \\
\mathrm{e} \\
\mathrm{s} \\
\mathrm{L} \\
\mathrm{i} \\
\mathrm{k} \\
\mathrm{e} \\
\mathrm{s}\end{array}$ & $\begin{array}{c}48 \\
37 . \\
3\end{array}$ & 2654.1 & $\begin{array}{c}1344 . \\
4\end{array}$ & 78.6 & 329.6 & 572.1 & $\begin{array}{c}2610 \\
.1\end{array}$ & 240.9 & 71.9 & 833 \\
\hline
\end{tabular}




\begin{tabular}{|c|c|c|c|c|c|c|c|c|c|c|}
\hline $\mathrm{F}$ & & & & & & & & & & \\
$\mathrm{o}$ & & & & & & & & & \\
1 & & & & & & & & & \\
1 & & & & & & & & & \\
$\mathrm{o}$ & & & & & & & & & \\
$\mathrm{W}$ & 10 & & & & & & & & & \\
$\mathrm{e}$ & 00 & & & & & & & & & \\
$\mathrm{r}$ & 00 & 30000 & 13000 & 1040 & 1930 & 14300 & 3280 & & \\
$\mathrm{~s}$ & 0 & 00 & 00 & 00 & 00 & 0 & 00 & 157000 & 00 & 0 \\
\hline
\end{tabular}

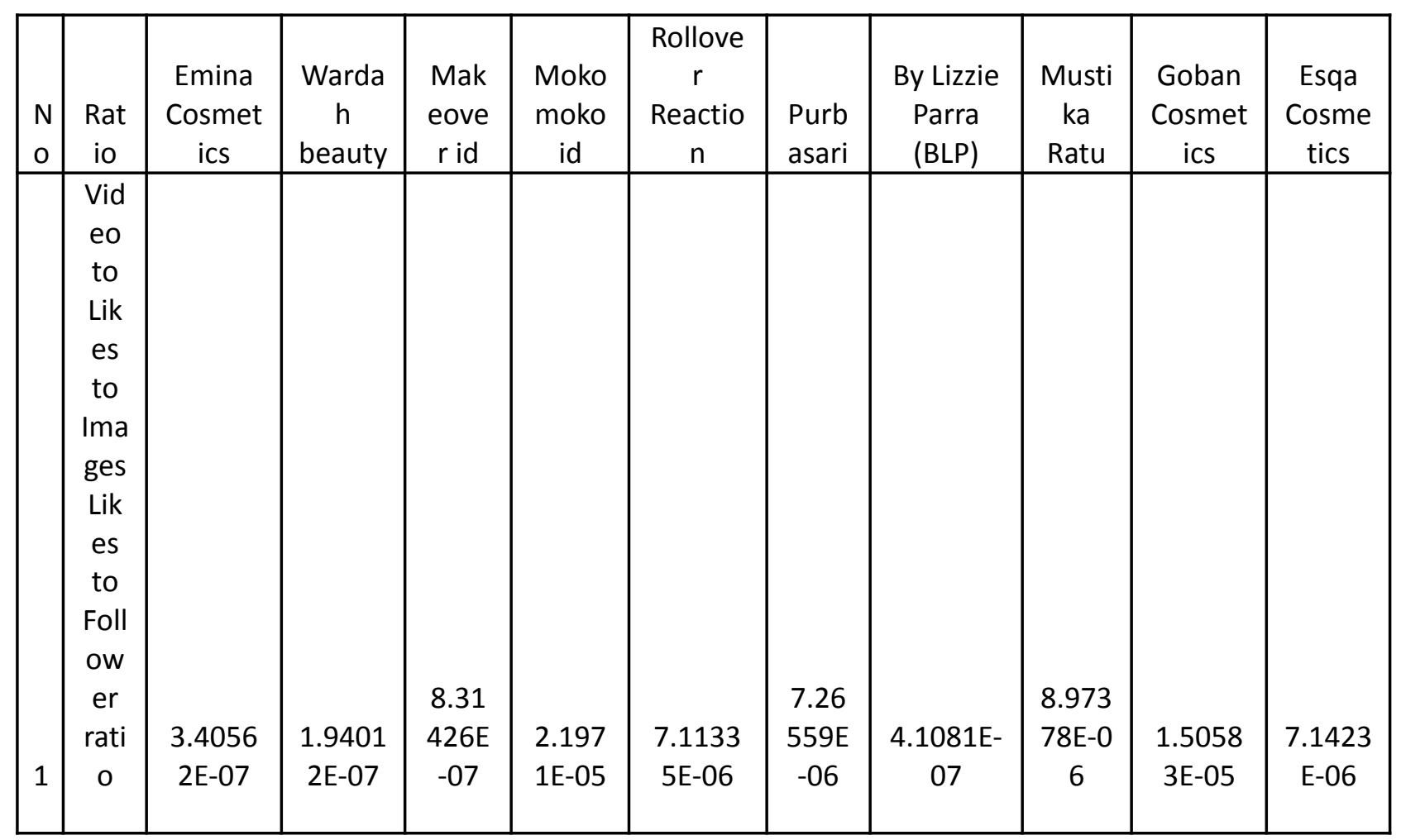

Nilai Rasio

\section{PERINGKAT}




\begin{tabular}{|l|c|c|c|c|c|c|c|c|c|c|}
\hline $\begin{array}{c}\text { Karak } \\
\text { teristi } \\
\mathrm{k}\end{array}$ & $\begin{array}{c}\text { Emina } \\
\text { Cosmet } \\
\text { ics }\end{array}$ & $\begin{array}{c}\text { Warda } \\
\mathrm{h} \\
\text { beauty }\end{array}$ & $\begin{array}{c}\text { Make } \\
\text { over } \\
\text { id }\end{array}$ & $\begin{array}{c}\text { Moko } \\
\text { moko } \\
\text { id }\end{array}$ & $\begin{array}{c}\text { Rollover } \\
\text { Reactio } \\
\mathrm{n}\end{array}$ & $\begin{array}{c}\text { Pur } \\
\text { bas } \\
\text { ari }\end{array}$ & $\begin{array}{c}\text { By Lizzie } \\
\text { Parra } \\
\text { (BLP) }\end{array}$ & $\begin{array}{c}\text { Musti } \\
\text { ka } \\
\text { Ratu }\end{array}$ & $\begin{array}{c}\text { Goban } \\
\text { Cosmeti } \\
\text { cs }\end{array}$ & $\begin{array}{c}\text { Esqa } \\
\text { Cosme } \\
\text { tics }\end{array}$ \\
\hline $\begin{array}{l}\text { Tingg } \\
\mathrm{i}\end{array}$ & 7 & 9 & 2 & 8 & 4 & 5 & 6 & 1 & 10 & 3 \\
\hline
\end{tabular}

\section{KESIMPULAN}

Tujuan dari penelitian ini adalah mengetahui kredibilitas performa dari akun Instagram 10 Merk Kosmetik Terbaik menggunakan Video Likes to Image Likes Ratio.

10 Merk Kosmetik Lokal Terbaik tersebut diantaranya : . eminacosmetics, wardahbeauty, makeoverid, mokomoko_id, rollover.reaction, purbasarimakeupid, blpbeauty, mustikaratuind, gobancosmetics, esqacosmetics Dari 10 brand kosmetik tersebut dapat disimpulkan bahwa :

1. Peringkat pertama diraih oleh mustikaratuind dengan nilai tertinggi yaitu $8.97378 \mathrm{E}-06$

2. Peringkat kedua diraih oleh makeoverid dengan nilai 8.31426E-07

3. Peringkat ketiga diraih oleh esqacosmetics dengan nilai 7.1423E-06

4. Peringkat keempat diraih oleh rollover.reaction dengan nilai 7.11335E-06

5. Peringkat kelima diraih oleh purbasarimakeupid dengan nilai 7.26559E-06

6. Peringkat keenam diraih oleh blpbeauty deng dengan nilai 4.1081E-07

7. Peringkat ketujuh diraih oleh eminacosmetics dengan nilai 3.40562E-07

8. Peringkat kedelapan diraih oleh mokomoko_id dengan nilai 2.1971E-05

9. Peringkat kesembilan diraih oleh wardahbeauty dengan nilai 1.94012E-07

10. Peringkat terendah diraih oleh gobancosmetics dengan nilai yaitu $1.50583 \mathrm{E}-05$

\section{DAFTAR PUSTAKA}


(Analisis Video Likes To Image Likes Ratio Instagram Pada 10 Merk Kosmetik Lokal Terbaik-19101002, n.d.) 